\title{
Disputas pela significação no discurso do HIV/aids: um percurso na ciência, na literatura, na militância LGBTI e nos canais do YouTube
}

\author{
Disputes for meaning in the discourse of HIV/AIDS: a journey in science, \\ literature, LGBTI activism and YouTube channels
}
Disputas por el significado en el discurso del VIH/SIDA: un viaje en ciencia, literatura, activismo LGBTI y canales de YouTube

Phelipe Rodrigues da Silva ${ }^{1, a}$

phlipeph81@gmail.com | https://orcid.org/o000-0002-6005-8517

Isaltina Mello Gomes ${ }^{1, b}$

isaltina@gmail.com | https://orcid.org/oooo-0003-2256-8564

\footnotetext{
${ }^{1}$ Universidade Federal de Pernambuco, Programa de Pós-Graduação em Comunicação. Recife, PE, Brasil.

a Mestrado em Comunicação pela Universidade Federal de Pernambuco.

${ }^{\text {b }}$ Doutorado em Linguística pela Universidade Federal de Pernambuco.
}

\section{RESUMO}

Este artigo trabalha na perspectiva histórica e na revisão bibliográfica de autores que analisam os recursos da linguagem, como a metáfora, para perceber a construção discursiva do HIV/aids na medicina, na mídia, no campo literário, na militância LGBTI e nos relatos em canais no YouTube de pessoas vivendo com HIV. O objetivo é utilizar as análises da terminologia e da história de luta pela significação de termos associados à doença e ao vírus em cada período. Dessa forma, verificamos que as representações iniciais sobre a condição clínica relacionada à culpa e ao julgamento moral de grupos, já vulneráveis antes da epidemia, não foram totalmente superadas no discurso. Observamos ainda os esforços, ao longo desses 40 anos, no campo da ciência para reduzir o estigma e a discriminação a partir da palavra.

Palavras-chave: HIV; Discurso; Redes sociais; Estereotipagem; Epidemias. 


\section{ABSTRACT}

This article works in the historical perspective and in the bibliographic review of authors who analyze language resources, such as the metaphor, to understand the discursive construction of HIV/AIDS in medicine, in the media, in the literary field, in LGBTI activism and in reports on YouTube channels of people living with HIV. The objective is to use the analysis of terminology and history of struggle for the meaning of terms associated with the disease and the virus in each period. We found that the initial representations about the clinical condition related to guilt and the moral judgment of groups, already vulnerable before the epidemic, were not completely overcome in the discourse. We also observe the efforts, over these 40 years, in the field of science to reduce stigma and discrimination based on words.

Keywords: HIV; Discourse; Social networks; Stereotyping; Epidemics.

\section{RESUMEN}

Este artículo trabaja en la perspectiva histórica y en la revisión bibliográfica de autores que analizan recursos del lenguaje, como la metáfora, para comprender la construcción discursiva del VIH/SIDA en la medicina, en los medios de comunicación, en el campo literario, en el activismo LGBTI y en canales de YouTube de personas que viven con el VIH. El objetivo es utilizar el análisis de la terminología y la historia de las luchas por el significado de los términos asociados a la enfermedad y al virus en cada período. Así, encontramos que las representaciones iniciales sobre el cuadro clínico relacionado con la culpa y el juicio moral de grupos, ya vulnerables antes de la epidemia, no fueron superadas por completo en el discurso. También hemos visto esfuerzos, durante estos 40 años, en el campo de la ciencia para reducir el estigma y la discriminación basados en las palabras.

Palabras clave: VIH; Discurso; Redes sociales; Estereotipo; Epidemias.

\section{Este artigo compõe o Dossiê Comunicação, Saúde e Crises Globais.}

Contribuição dos autores:

Concepção e desenho do estudo: Phelipe Rodrigues da Silva e Isaltina Mello Gomes.

Aquisição, análise ou interpretação dos dados: Phelipe Rodrigues da Silva.

Redação do manuscrito: Phelipe Rodrigues da Silva.

Revisão crítica do conteúdo intelectual: Isaltina Mello Gomes.

Declaração de conflito de interesses: não há.

Fontes de financiamento: Fundação de Amparo à Ciência e Tecnologia do Estado de Pernambuco (Facepe).

Considerações éticas: não há.

Agradecimentos/Contribuições adicionais: não há.

Histórico do artigo: submetido: 8 set. 2020 | aceito: 6 nov. 2020 | publicado: 17 dez. 2020.

Apresentação anterior: não houve.

Licença CC BY-NC atribuição não comercial. Com essa licença é permitido acessar, baixar (download), copiar, imprimir, compartilhar, reutilizar e distribuir os artigos, desde que para uso não comercial e com a citação da fonte, conferindo os devidos créditos de autoria e menção à Reciis. Nesses casos, nenhuma permissão é necessária por parte dos autores ou dos editores. 


\section{INTRODUÇÃO}

Em 2021, faz exatamente 40 anos que o Centro de Controle e Prevenção de Doenças dos Estados Unidos (CDC $)^{1}$ publicou o comunicado em seu Relatório Semanal de Morbidade e Mortalidade (MMWR) sobre casos de uma infecção pulmonar em cinco jovens gays, brancos, previamente saudáveis, moradores de Los Angeles. No dia 5 de junho de 1981, o médico Michael Gottlieb, o imunologista, Wayne Shandera, integrante do CDC, e alguns colegas relataram que todos os homens também tinham outras infecções incomuns, indicando que o sistema imunológico deles estava falhando. Esse teria sido o primeiro relato oficial do que seria conhecida como pandemia de aids (Síndrome de Imunodeficiência Adquirida). Naquele mesmo dia, o dermatologista Alvin Friedman-Kien, de Nova York, informava ao órgão federal norte-americano casos do sarcoma de Kaposi, um tipo de câncer também incomum, em gays jovens de Nova York e também da Califórnia. Horas mais tarde, as informações estavam disponíveis na Associated Press, no Los Angeles Times e no San Francisco Chronicle ${ }^{1}$.

A aids aparecia, quase simultaneamente, no boletim científico, nas páginas dos dois jornais e no banco de dados de uma das maiores agências de notícias do mundo. A partir da divulgação de uma condição clínica associada a um grupo específico de pessoas, os homossexuais do sexo masculino, mostrou-se urgente avançar nas análises e nos questionamentos da forma de narrar da ciência, que parecia amparada na neutralidade e na objetividade ${ }^{2}$.

Paula Treichler ${ }^{3}$ observou que, embora tratando-se de uma síndrome real, causada por um vírus, a relação entre realidade e linguagem é algo sempre complicado, seja para o campo científico ou para todo "o resto de nós" (p.195) ${ }^{3}$, como marca a autora. "Embora tenhamos chegado a aceitar as descobertas da ciência biomédica como caracterizações precisas da realidade material, os discursos científicos e médicos são provisórios e apenas 'verdadeiros' ou 'reais' de certas maneiras específicas - na confirmação de descobertas de pesquisas anteriores, por exemplo, ou na promoção de tratamentos clínicos eficazes" (p. 195)3. No caso da aids, a autora nos lembra que o nome não apenas classificou o quadro clínico, mas ajudou a construir a doença, trazendo consigo as operações semânticas relacionadas a ela.

Naquele primeiro momento, os sintomas descritos pelo Relatório Semanal do CDC não só eram relatados como exclusivos em homens gays, "mas eles tinham histórias de múltiplos parceiros e de múltiplas doenças sexualmente transmissíveis" (p. 198)3. Antes que o termo AIDS (Acquired Immune Deficiency Syndrome) fosse usado pela primeira vez, em setembro de 1982, pelo $\mathrm{CDC}^{1}$, representações construídas sobre o grupo de pessoas que ela atingia deram origem a expressões não oficiais. Foi o caso de 'pneumonia gay', 'câncer gay' e, de todos, o mais carregado de estigma - WOGS -, sigla em inglês para Síndrome da Ira de Deus - esses eram alguns dos termos que constavam da lista. Essa nomenclatura trazia a questão da promiscuidade e da culpa sexual para demarcar a fronteira entre a 'população em geral' e aqueles que estavam no grupo prioritário das infecções.

Nos Estados Unidos, observou Susan Sontag 4 , os que estavam protegidos eram os "heterossexuais brancos que não usavam drogas injetáveis nem tinham relações sexuais com pessoas que o fazem" (p. 34)4. A aids foi concebida como "um mal que ataca um grupo perigoso de pessoas diferentes e já estigmatizadas" (p. 34) ${ }^{4}$, da mesma maneira que a sífilis.

As abordagens sobre a síndrome entre profissionais de saúde e burocratas que trabalhavam na epidemiologia exigiram análises e geraram questionamentos por parte de intelectuais das ciências humanas, por membros da comunidade homossexual e pelos ativistas da aids. Entre eles, o pesquisador e escritor britânico Simon Watney tornou-se figura central nos estudos sobre os aspectos sociais da epidemia. Autor do clássico artigo The spectacle of AIDS $^{5}$, Watney é reconhecido por cientistas que investigam o 
tema desde os primeiros anos, como o antropólogo Richard Parker, por suas contribuições inovadoras, a exemplo também de seu célebre ensaio Safer sex as community practice ${ }^{6}$. Na opinião de Parker, este ensaio de Simon Watney é ainda "uma das coisas mais perspicazes e inspiradoras escritas sobre a resposta da comunidade gay à AIDS no começo da epidemia”. De acordo com Treichler³, Watney "nos prepara para analisar a AIDS em relação a questões de linguagem, representação, mobilização de narrativas culturais, ideologia, diferenças e hierarquias sociais e intelectuais, divisões binárias, interpretação e concursos de significado" (p. 213)3. O dramaturgo norteamericano Larry Kramer, cofundador do Gay Men’s Health Crisis (GMHC) ${ }^{8}$, em 1982, e autor da peça The Normal Heart, de 1985, se destacou pelo seu ativismo político em prol da comunidade de Lésbicas, Gays, Bissexuais e Transsexuais (LGBT), pela sua militância, no campo das artes e ao longo de sua vida, na defesa dos direitos das pessoas com aids e na luta para combater a crise da doença e seus preconceitos.

Quando as notícias sobre a 'síndrome gay' chegaram ao Brasil, em 1982, antes mesmo que os primeiros casos fossem notificados no país ${ }^{9}$, já havia uma primeira camada de significados trazida de fora e a percepção da necessidade de lutar pelo discurso da aids entre uma parte da comunidade homossexualii no país. A apropriação discursiva sobre o tema deu-se, em São Paulo, muito rapidamente com artistas e intelectuais dissidentes do Grupo Somos, que uniram forças para criar junto com a Secretaria de Saúde do governo de Franco Montoro o primeiro programa de atenção à aids no país, em 1983 $3^{10}$. "Antônio Carlos Tosta, líder do grupo Outra Coisa - Ação Homossexualista, remanescente do Somos, tomou a iniciativa de distribuir, nos principais locais de encontro homossexual, folhetos de advertência sobre a doença, antes mesmo das primeiras ações governamentais" (p. 22) ${ }^{10}$. Na reconstituição histórica da aids no Brasil, de 1983 a 2003, Laurindo-Teodorescu e Teixeira observam que era evidente o protagonismo dos homens gays, marcando que "os profissionais de saúde não teriam o monopólio do discurso sobre a aids" (p.21) ${ }^{10}$.

Já nas primeiras palestras organizadas em São Paulo, quando termos como 'promiscuidade' e 'culpa', que constavam dos boletins de saúde dos Estados Unidos, apareciam nos debates, eles eram questionados e rebatidos. A atuação dos ativistas, acompanhando a evolução das pesquisas sobre o HIV (sobre a aids), aparece na evolução da terminologia, no discurso e na palavra que "é capaz de fixar todas as fases transitórias das mudanças sociais, por mais delicadas e passageiras que elas sejam" (p. 106) ${ }^{11}$. Ao longo das últimas quatro décadas, surgiram variadas formas de operar, o que Paula Treichler chama de jogo semântico do HIV, da aids, com a inserção de canais do YouTube de pessoas vivendo com vírus, a partir das novas ferramentas tecnológicas, como veremos adiante.

\section{TERMINOLOGIA, ESTIGMA E GRUPO DE RISCO}

As alterações na forma de abordar o HIV/aids e os casos de pessoas que vivem e convivem com o vírus começam a aparecer nos resumos dos trabalhos científicos apresentados na Conferência Internacional de Aids (IAC, sigla em inglês do evento), com destaque para o artigo Trends in HIV terminology: text mining and data visualization assessment of international AIDS conference abstracts over 25 years $^{12}$. Essas modificações estão reunidas neste material que abrange os anos de 1989 a 2014, com a análise quantitativa no tratamento usado pelos pesquisadores para reduzir, através da linguagem, o estigma relacionado ao vírus. Na terminologia do HIV é possível notar, a partir da inclusão, do desaparecimento e mesmo da alteração de alguns termos, os avanços tanto nos textos das pesquisas quanto na prática médica, tornando a comunicação dos profissionais da área da saúde com as pessoas que vivem ou convivem com o HIV mais eficaz ${ }^{12}$. Nesse artigo citado, há recomendações de termos atualizados e ainda aqueles que caíram em desuso. Em 2008, por exemplo, 'portadores do HIV' ou 'vítimas' praticamente desapareceram dos

ii No artigo, as expressões movimento homossexual e militância LGBTI marcam dois momentos distintos da luta pelos direitos civis no contexto brasileiro. 
resumos na Conferência Internacional de Aids, dando lugar à 'pessoa vivendo com HIV', por privilegiar a pessoa antes de sua condição de saúde. Linguagens em textos científicos ou mesmo na prática médica que atribuam culpa também são desencorajadas, quebrando o ciclo das primeiras construções de significado, abordadas na Introdução. No estudo em questão, termos como 'gay' e 'homossexual', para se referir a pessoas ou grupos, na Conferência Internacional de Aids de 2014, foram substituídos por 'homens que fazem sexo com homens'. Os pesquisadores são claros ao afirmarem que "os esforços para reduzir ou zerar o estigma do HIV e, mais importante, facilitará a comunicação eficaz entre os profissionais de saúde e as pessoas afetadas pelo HIV" (p. 12) ${ }^{12}$.

Entre os brasileiros, o Índice de Estigma em Relação às Pessoas Vivendo com HIV/aids ${ }^{13}$ mapeou, em sete capitais do país, as experiências de 1.784 pessoas. O Programa Conjunto das Nações Unidas sobre HIV/ aids (UNAIDS) apresentou em dezembro de 2019 as conclusões obtidas a partir da metodologia global já aplicada em mais de 100 países para detectar e medir a mudança de tendências em relação ao estigma e à discriminação. Da população entrevistada, $64,1 \%$ das pessoas sofreram alguma forma de preconceito por conta da sorologia positiva para o vírus. Os comentários discriminatórios ou especulativos são as formas mais vivenciadas de segregação e isolamento para as pessoas soropositivas, em 46,3\% das respostas. Desse universo, $41 \%$ diziam ter sido alvo de comentários feitos por membros da própria família. Outras abordagens discriminatórias relatadas foram: assédio verbal (25,3\%), perda de fonte de renda ou do emprego (19,6\%) e agressões físicas $(6,0 \%)$.

Na história da epidemia de aids, ao longo desses 40 anos, o conceito de 'grupo de risco' ainda carrega em sua construção o estigma relacionado à promiscuidade e culpa sexual. Os homossexuais foram os primeiros a carregar a marca, em sentido figurado, da Doença dos $5 \mathrm{H}$, junto com os usuários de drogas injetáveis (heroinômanos), trabalhadoras do sexo (em inglês, usava-se a expressão ofensiva hooker nos anos 1980), hemofílicos e haitianos, criando uma espécie de fronteira ${ }^{14}$. Quando uma doença sem identificação surge, como foi a aids em 1981, as mudanças no ambiente social geram insegurança e reconfigurações em vários campos, sendo o campo linguístico um dos primeiros a representar a separação entre nós e eles, entre nós e os que estão em risco. No caso das pessoas que eram associadas à síndrome, as representações sociais já estavam ligadas às comunidades vulneráveis anteriormente e a um grupo de fora do hegemônico. Porque a nova doença epidêmica também foi "ligada a nações estrangeiras e a grupos marginais" (p. 297) ${ }^{15}$.

Em vários momentos da história da humanidade, esses recursos foram utilizados para uma construção de sentido, porque "é no mundo das representações que administramos nosso medo da doença, isolando-o com tanta certeza como se o tivéssemos colocado em quarentena. Mas dentro desse isolamento, os ícones permanecem visíveis para todos nós, prova de que ainda estamos inteiros, saudáveis e sãos; que não somos diferentes, doentes ou loucos" (p. 107) ${ }^{14}$. Na condição do outro, do diferente, aparece o eixo da construção discursiva nos relatos sobre a aids "[...] o núcleo central do 'outro' é um instrumento projetivo de defesa" (p. 310) ${ }^{15}$. Ao se identificar a nova doença às epidemias do passado, como a sífilis, "o laço entre grupos estranhos, aberração e doença voltou à cena principal nas representações sociais da Aids" (p. 310) ${ }^{15}$. A sífilis e a lepra "foram as primeiras doenças a serem sistematicamente encaradas como repulsivas" (p. 55) . Foi a sífilis que, nas primeiras descrições feitas por médicos, no final do século XV, gerou uma versão das metáforas que proliferaram em torno da aids: a ideia de uma doença que não trazia apenas repulsa e punição, como também representava uma invasão que atingia toda a coletividade ${ }^{4}$.

Nesse aspecto, a aids diferencia-se do câncer, "doença provocada pelos hábitos do indivíduo"4, como aponta Susan Sontag em AIDS e suas metáforas, mostrando que a aids foi "concebida de maneira pré-moderna, como uma doença provocada pelo indivíduo enquanto tal e enquanto membro de algum grupo de risco - essa categoria burocrática e aparentemente neutra" (p. 56)4. No entanto, essa terminologia retoma "a ideia arcaica de uma comunidade polú́da para a qual a doença representa uma condenação" (p. 55-56)4. Na opinião de Bessa, a autora não tentou comparar outras epidemias com a de HIV/aids, sendo o seu intento "menos incluí-la em uma 
série de doenças e epidemias ao longo da história, naturalizando-a" (p. 19) ${ }^{16}$. Sontag retornava à história para citar metáforas militares como 'batalha', 'luta', e, sobretudo, a principal imagem, a da 'peste', que remetia ao que de pior poderia existir sobre doenças. Susan Sontag parte das metáforas usadas em outras epidemias para particularizar a aids na sua análise. Essa observação é importante para percebermos os "campos ideológicos que a acompanham e amoldam [a aids], ao se utilizarem de certas metáforas, para determinar um controle não especificamente epidemiológico, mas, principalmente, discursivo" (p. 17) ${ }^{16}$.

A aids, já no seu início, afetou as mais diversas esferas discursivas: na medicina, na política, na sexualidade, gerando o que Treichler aponta como "epidemia de signficados" (p.32) ${ }^{17}$. Não se pode abandonar a perspectiva de perigo real, concreto da síndrome. "No entanto, a epidemia de Aids - com seu genuíno potencial de devastação global - é simultaneamente uma epidemia de uma doença letal transmissível e uma epidemia de sentidos ou de significados" (p. 32) ${ }^{17}$.

Essa construção narrativa sobre a aids foi produzida num conjunto amplo, que tem, além da medicina, ciência e poder público, jornais e revistas, programas televisivos e de rádio, nos anos 1980, ou seja, todo um conjunto enorme engendrando discursos e desdobramentos. No Brasil daquele período, uma parte da mídia chegou mesmo a incitar a violência contra o grupo considerado responsável pelas infecções, sobretudo, os homossexuais ${ }^{18}$. A difusão, nos meios de comunicação de massa, vai gerar "a construção de um novo fenômeno social: a AIDS-notícia. Para além de uma doença e de uma epidemia, a AIDS tornou-se um fenômeno social marcado por tecnologias modernas no campo das pesquisas médicas, pelo ativismo social e pela impressionante dimensão midiática que assumiu" (p. 852) ${ }^{19}$. Embora exista o aspecto do preconceito e do sensacionalismo das notícias, não se pode deixar de observar que a mídia se colocava "como o principal, e quase único, meio de informação, sobretudo, dada a abrangência nacional de alguns veículos de comunicação" (p.49)9 . Jane Galvão destaca que a mídia foi um segmento do setor privado responsável por dar respostas sobre a aids, antes da criação de um programa nacional, que tomou forma somente em $1986^{9}$.

\section{'COMO PEGOU?': O VOYEURISMO E AS ESTRATÉGIAS CONTRA O ESTIGMA}

O conceito de 'grupo de risco', abordado anteriormente, operava no sentido da dupla confissão, visto que a homossexualidade, mesmo em grandes cidades, era vivida na clandestinidade ${ }^{20}$. "Com a Aids revelou-se o aspecto mais trágico dessa situação de vida na sombra. Para muitos, o pior não é a doença; é a necessidade de se revelar homossexual. De um modo patético, o doente de Aids é obrigado a revelar a forma de sua contaminação. É a transformação do diagnóstico numa denúncia" (p. 46-47) ${ }^{20}$. A própria medicina, assinalava um "fascínio quase voyeurista. Alguns médicos perguntavam ao saber de um novo caso de AIDS em pacientes do sexo masculino: '- Como pegou?' Tudo o mais deixa de ter importância" (p. 141)².

Nas entrevistas feitas para a sua tese, Kenneth Rochel de Camargo Jr. apresentou as respostas de uma médica que trazia uma hipótese a respeito da curiosidade de alguns profissionais: "presumivelmente heterossexuais, para sentirem-se protegidos em suas atividades sexuais, em especial, as 'clandestinas' ('escapadinhas')" (p. 141)². Essa era uma tentativa de negar que a infecção se daria de mulheres para homens, desprezando mesmo a heterossexualidade da aids no continente africano ${ }^{4}$. O desacordo sobre a infecção por heterossexuais alcançaria o grau máximo quando um dos entrevistados chegou a relatar que ele e outros médicos gostariam de dispor de um exame de detecção para anticorpos antiespermatozoides. O que seria, na prática, uma proposição de 'teste da homossexualidade', algo parecido com a detecção de anticorpos anti-HIV nos testes simples para o vírus, com o ELISA (Enzyme-Linked Immunosorbent Assay), que foi adotado a partir de 1985. Vale destacar outra resposta encontrada nas entrevistas: "[...] '- Aí eu queria ver o homem soropositivo que ia negar ser bicha”" (p. 142)². No ambiente clínico-hospitalar, aventou-se ainda que, por vias indiretas, havia maior chance de um homem com práticas homoeróticas negá-las do que um usuário 
de drogas ocultar o uso de alguma substância. Essa seria, talvez, uma sugestão da hierarquia valorativa na discriminação, sendo homossexual pior que 'viciado’2.

Diante de uma análise como essa, chega-se ao que Susan Sontag observa como uma dupla genealogia metafórica da aids. "Enquanto microprocesso, ela é encarada como o câncer: como uma invasão" (p.21-22)4. Embora, neste último, as representações militares se afastem da causalidade que o agente infeccioso, usado para construir a ideia de aids, carrega. Quando se abordava a transmissão do vírus, a poluição era associada à sífilis, acionando a metáfora mais antiga, a da peste, em que a doença e os doentes eram considerados o mal ${ }^{4}$. Em AIDS e suas metáforas ${ }^{4}$, obra fundamental para a compreensão das interpretações utilizadas para descrever uma doença que se apresentava como novidade, nos anos 1980, Sontag aborda a paranoia política e "atmosfera de ficção científica" (p.23) que já se apresentavam nos textos sobre o câncer e ganham acentos mais fortes para descrição da aids. A autora cita, inclusive, um texto da revista Time, de 1986, como exemplar, sobre essa guerra do vírus contra as células de defesa do organismo ${ }^{4}$. O corpo atingido pela síndrome revelava-se, ainda, 'impuro', seja pela sexualidade desviante dos padrões ditos 'normais', seja pela culpa desenvolvida e atribuída ao doente, que trazia o poder de disseminar o vírus para outras pessoas ${ }^{21}$.

Nos textos sobre infecções sexualmente transmissíveis, nem mesmo a cristalina, a afecção que foi, no século XVIII, uma espécie de confissão de atentado contra a moral ${ }^{21}$, teve o peso estigmatizante da aids para a sociedade. Caracterizada pela aparição de tumores cheios de um líquido translúcido sobre o prepúcio ou na região anal, a cristalina era denúncia de "prática contra a natureza, o mal e o castigo dos homossexuais" (p.24) ${ }^{22}$, devendo ser denunciada ao chefe de polícia, antes do atendimento clínico. A letalidade era elevada, matando 9 de cada 10 casos da infecção ${ }^{22}$. Mas um aspecto fundamental separa as duas doenças: a mais antiga não chegou ao conhecimento público, enquanto a aids já surgiria nos meios de comunicação de massa, tornando-se um tópico de destaque na mídia. Ter o nome vinculado à doença revelava não só o medo de morrer, mas o temor do estigma, trazendo à tona um traço da homofobia já cultivada em toda a sociedade.

O estigma relacionado aos doentes de aids e a associação com a homossexualidade dificultaram, inclusive, estratégias de prevenção e estudos para checagem sobre maior prevalência de infecção por HIV entre homens que fazem sexo com homens (HSH). No Brasil, a estimativa da infecção pelo HIV, na população de $\mathrm{HSH}$, era desconhecida até 2009, quando foi realizada a primeira pesquisa nesse grupo. "A sociedade civil, representada por ONG's que atuavam fortemente junto a esta população e ao governo, vinha tentando postergar um estudo entre a comunidade receando que os resultados pudessem aumentar o estigma e a discriminação contra eles. Por outro lado, desconhecer a real situação levava recursos de prevenção para outras áreas”²3.

Em 2016, uma segunda pesquisa em 12 capitais brasileiras mostrou que a taxa de prevalência nessa população-chave para infecções pelo vírus chegava a 18,4\%, dentro do universo analisado, sendo 46 vezes maior do que o percentual na população em geral ${ }^{23}$. Uma das razões apontadas pela coordenadora do mapeamento seria a intensa redução das medidas preventivas voltadas a essas populações específicas que se iniciou logo após a realização do estudo anterior. Campanhas governamentais foram coibidas por interferência direta das bancadas armamentista, ruralista e evangélica no Congresso $\mathrm{Nacional}^{23}$. Os dados não podem ser interpretados sem levar em consideração a alta carga de discriminação que ainda pesa sobre métodos de prevenção, sejam eles o preservativo externo ou as tecnologias mais recentes para proteção combinada ao HIV, como a Profilaxia Pré-Exposição (PrEP), possibilidade surgida no início dos anos 2000. A medicação, que deve ser tomada diariamente para evitar a infecção pelo vírus, foi adotada a partir de 2004, com o nome comercial de Truvada, nos Estados Unidos. O nível de preconceito com as pessoas que começaram a utilizar a PrEP foi verificado em expressões como 'Truvada whore', algo como 'puta da Truvada'. "A expressão pejorativa, destinada especialmente para homens gays, revela a associação do então novo método preventivo com identidades sexuais, reavivando preconceitos históricos, como da associação da homossexualidade com a promiscuidade" (p. 254) ${ }^{24}$. 
Um exemplo desse preconceito pode ser observado na publicação da revista Época, em abril de 2018, edição de n. 1.031, na reportagem "A outra pílula azul”², com chamada de capa sobre a chegada da PrEP no Sistema Único de Saúde (SUS). A reação das instituições que trabalham para combater a discriminação e garantir os direitos das políticas para prevenção ao HIV foi imediata, ao alertar, por exemplo, como a profilaxia era apresentada na reportagem. 'Erros primários' foram apontados, como confundir PrEP e PEP (Profilaxia Pós-Exposição), outro método preventivo, lançado pelo Ministério da Saúde em 2010. Ainda em fase de implementação, a PrEP não poderia ser responsabilizada "por mudanças epidemiológicas em anos anteriores" ${ }^{25}$. As entidades da sociedade civil perceberam a necessidade de intervenção e as respostas mostraram que "os sentidos da militância LGBTI certamente têm se ampliado, com a incorporação de novas estratégias de ação e novas atrizes e novos atores, convivendo com antigas entidades, coletivos e ONGs" (p. 255) ${ }^{24}$.

Atuações na internet, com a multiplicação de canais no YouTube, contribuem mais recentemente para uma nova possibilidade contra a estigmatização, com a promoção de "visibilidade para vivências e experiências LGBTI que priorizam o protagonismo na fala sobre si e buscam constituir uma alternativa à falta de narrativas, o que é conhecido e frequentemente lembrado nos debates do movimento como ausência de representatividade, ou à circulação de narrativas equivocadas a respeito desses sujeitos que compõem a sopa de letrinhas" (p. 255) ${ }^{24}$.

Canais como o Super indetectável, de João Geraldo Netto, e Confissões de um soropositivo, de Leonardo Cezimbra, dois dos primeiros youtubers a falar abertamente sobre a sorologia positiva para o HIV, no YouTube, "emergem como promotores de visibilidade para pessoas que, após descobrirem a sorologia positiva para o HIV" (p. 255) 24 , podem agora mostrar suas vozes ao mundo. A narrativa em rede de pessoas vivendo com o vírus aproxima-se, em sua forma, do processo terapêutico, mas também traz características de um projeto de educação em saúde sexual que pode alinhavar militância, vigilância e entretenimento ${ }^{26}$. Neste caso, uma proposta de informação para prevenção a riscos ligada a um cuidado de si, que é percebida ostensivamente no discurso dos youtubers que reafirmam a ausência de informações para o jovem na faixa mais vulnerável para novas infecções, entre os 15 anos e 24 anos $^{27}$.

\section{O TRAÇO COLETIVO NOS RELATOS AUTOBIOGRÁFICOS}

Essas narrativas biográficas no YouTube trazem uma articulação indissociável entre o 'eu' e o 'nós', carregando um movimento dialógico que abarca contradições sem separar o mundo público do particular, do privado ${ }^{28}$. Não é possível negar esse vai e vem constitutivo nos relatos sobre a revelação da sorologia positiva para o HIV nos canais do YouTube. Para compreender o fenômeno dos vídeos compartilhados sobre uma nova vivência do HIV, como condição crônica atualmente, recorremos às pesquisas de Leonor Arfuch, que faz um percurso teórico pelos estudos de linguística e sociologia de Mikhail Bakhtin e Norbert Elias, "ambos inscritos no tronco da tradição filosófica alemã, reconhecendo a influência comum pela filosofia de Martin Buber" (p. 92) ${ }^{28}$.

Nessa perspectiva apresentada pela pesquisadora argentina, Leonor Arfuch, existe a possibilidade de se avistar com "o eu verdadeiro, o mais íntimo e pessoal, aquele que expressa pensamentos, convicções, reações afetivas, traços de caráter, [este eu] se conformará não mais no abismo que a sociedade viria avassalar, mas justamente nessa trama de relações sociais da qual emerge e na qual se inscreve" (p. 93) ${ }^{28}$. Aqui, há a necessidade de olhar para o projeto político, o que Arfuch denomina de uma "acentuação qualitativa da democracia", que vai além "do caso singular e da pequena história" (p. 100) ${ }^{28}$

A biografia de cada um desses youtubers que revela a sorologia positiva do HIV precisa ser analisada em contexto, sem abandonar o fio histórico, para encontrar o papel da literatura e dos grupos envolvidos nas primeiras produções de significados, percebendo aqui um outro tipo de ativismo sobre o HIV/aids que traz em suas teias discursivas um acento pronunciado da autobiografia. "Essas novas narrativas, identificações, identidades (políticas, étnicas, culturais, religiosas, genéricas, sexuais etc.), novos modelos de vida possíveis, cuja a 
manifestação à luz do público supõe a pugna e o conflito, assim como uma revalorização de uma ideia mesma de minoria, não necessariamente na chave do menor em número ou importância, mas, precisamente, no sentido de Deleuze, como diferenciação da norma - ou da 'normalidade', sempre majoritária, ou da hegemonia - que é desse modo desafiada" (p. 100-101) $)^{28}$.

O conceito de hegemonia, aqui adotado por Leonor Arfuch, é baseado em Ernesto Laclau e Chantal Mouffe, em que o conteúdo particular passa a ser investido como universal, "aparecendo assim como o nome de uma plenitude ausente, que é na verdade irredutível à autorrepresentação" (p. 101) ${ }^{28}$. Há que se perceber, como a autora destaca, nessas relações, nesses embates, que "nenhuma nova posição de enunciado advém de graça no espaço discursivo social -, o desafio é, justamente, achar uma voz autobiográfica em seus acentos coletivos - que possa dar sentido a um mito de origem, a uma genealogia, a um devir - e defender, portanto, alguma condição de existência" (p. 101) ${ }^{28}$. É nesse espaço conceitual que são revistas as linguagens, os discursos dos canais no YouTube e, ainda, a produção literária da era pré e pós-coquetel, como veremos no próximo tópico.

\section{AS VÁRIAS CAMADAS SEMÂNTICAS SOBRE O VÍRUS NA LITERATURA}

A percepção da epidemia da aids e do vírus HIV construída pela imprensa, pelo discurso médico, pelos documentos científicos e pela produção artística traz várias camadas de significação, ao longo desses 40 anos. Cada período apresenta suas especificidades, sendo a literatura um dos caminhos para a leitura da síndrome que, naquele primeiro momento, era construída a partir da não ficção. É o caso, em 1983, dois anos após o anúncio do CDC, da obra Como fazer sexo em uma epidemia, de Michael Callen e Richard Berkowitz. uma espécie de manual e uma das primeiras publicações a recomendar o uso de preservativos no qual temos o cuidado e a prevenção de homens gays feitos para outros homens gays. O livro, AIDS literature and gay identity: the literature of $\operatorname{loss}^{29}$ (sem edição no Brasil), fruto de vasta pesquisa, Monica B. Pearl cita essas obras que faziam sentido em meio ao pânico e ao excesso de informações, a maioria desencontrada, vindas da imprensa do período.

Segundo Monica B. Pearl, um livro como o de Callen e Berkowitz consistia em "uma resposta prudente e convincente à crise, sem alarmes nem medidas draconianas em relação ao sexo" (p. 3) 2 $^{29}$. A tentativa era a de compreender o que estava acontecendo diante daquela avalanche de representações, numa tentativa de não se perder no excesso de informações, o que Pearl denomina de um período de "vertigem narrativa", algo que as epidemias, carregadas de mistério e de metáforas, trazem consigo. Após esse período de descobertas e conjecturas da mídia, da ciência e dos grupos diretamente envolvidos nas narrativas sobre a aids, surgiriam, em 1988, ou seja, sete anos depois das primeiras notícias, os romances e contos sobre a doença. E, mais que isso, com alta qualidade artística, sendo essa ficção sobre aids, em geral, uma ficção considerada gay.

Deve ficar claro que "a produção literária dos anos 1980 era feita por homens gays sobre homens gays. Quase não havia relatos de outros grupos afetados, como mulheres ou usuários de drogas" (p. 3$)^{29}$.

A tentativa de compreender a estrutura dos relatos confessionais surgidos, sobretudo, a partir da segunda metade dos anos 1990, ocorre quando "começa a se consolidar uma nova tradição, espécie de desdobramento da gay and lesbian fiction, que pode ser chamada de 'literatura de aids', 'narrativa(s) de aids' ou, ainda, 'ficção/fições da aids' na esteira das discussões propostas por Pearl” (p 3) 30 $^{30}$ Uma investigação das obras com acento confessional sobre a aids, produzidas entre os anos 1990 e as primeiras décadas do novo milênio no Brasil, aponta como uma das referências o livro autobiográfico O segundo armário: diário de um jovem soropositivo (2016), de Gabriel de Souza Abreu ${ }^{30}$. Outras publicações que se destacaram e que partem da narrativa autobiográfica são: Cinema Orly (1999), de Luís Capucho, romance que trata da experiência/vivência da aids. E o maior fenômeno do mercado editorial brasileiro, nesse segmento, a obra de Valéria Piassa Polizzi, publicada pela Editora Ática, em 1997. O livro intitulado Depois daquela viagem: diário de bordo de uma jovem que aprendeu a viver com aids narra a história de uma adolescente heterossexual que contraiu o vírus HIV do 
namorado. “Ao contrário das narrativas de aids que retratam a década de 1980, esses três artefatos culturais relatam enredos ficcionais que se passam já ao longo das décadas de 1990 ou dos anos 2000, momentos históricos nos quais tanto a síndrome quanto o vírus a ela associado já estão recobertos por algumas camadas semânticas, muito em função das metáforas e alegorias criadas ao longo da década de 1980 para significar culturalmente a aparição de um quadro clínico (ou, ainda, de uma sintomatologia) até então sem antecedentes” (p. 5) ${ }^{30}$.

Mas é preciso cuidado com os discursos da aids, daquele período específico, reunidos na literatura ficcional e nos relatos, ao tentar compreender de que maneira existe, ou se configura como lacuna, uma reverberação no intertexto encontrado, atualmente, nos canais do YouTube de pessoas que vivem com HIV. Ainda existem histórias de julgamento moral e medo da morte no momento do diagnóstico, relatadas em boa parte dos canais. Ao se analisar os primeiros anos e as histórias que vieram a seguir, incluindo-se os textos produzidos atualmente, não se pode cair na tentação de se fazer uma leitura contemporânea com bases fincadas num contexto da realidade atual do HIV/aids - não é a mesma condição, cada texto tem seu tempo, seu contexto. Desde a terapia dos inibidores de protease, apresentada em 1996, na Conferência Internacional de Aids, em Vancouver, muitas questões foram alteradas: a resposta da medicina ao oferecer tratamento para tornar o HIV uma condição crônica; o enfrentamento dos conceitos cristalizados nos anos iniciais que foram revistos ao longo do tempo; além das críticas, por uma parte dos ativistas, a esse processo de cronificação do vírus. "Cada uma dessas décadas teve suas próprias idiossincrasias históricas com relação aos processos de narrativização da aids, ou mesmo com os diferentes graus de estigma que eram associados à infecção pelo vírus HIV nessas diferentes décadas. Chamo a atenção, entretanto, que todos os artefatos culturais que menciono ao longo dessa discussão reportam, em seus universos ficcionais, à década de 1980 e ao momento mais crítico da 'aparição' da aids como fenômeno social a ser significado" (p. 4) ${ }^{30}$.

Portanto, trabalhar com a perspectiva da época, observando-se as manifestações de construção de uma identidade positiva para o HIV, hoje, é caminho para perceber que a metáfora não significa um problema. É preciso considerar a crítica de Susan Sontag e não desprezar o valor das metáforas ou das elipses adotadas pela autora já em Assim vivemos agora ${ }^{31}$, seu primeiro texto sobre a aids. Outros autores, como Caio Fernando Abreu, seguiram a mesma trilha, ao subtrair o termo aids sem comprometer a compreensão, exigindo atenção e cuidado do leitor. Essa aparente ‘supressão', que na verdade é uma ‘substituição', pode ser vista no uso de outros elementos, como o espelho - um 'artifício' que será percebido em obras que inauguram uma nova narrativa sobre a aids, na primeira década e meia após o aparecimento da síndrome ${ }^{16}$. O espelho carrega um sentido de "alteridade na epidemia discursiva da AIDS, que parece ser o ponto crucial. [...] [A] AIDS é percebida e vivenciada como uma doença do outro, daquele que é visto como estranho, diferente, marginal à sua própria sociedade"16 (p. 88).

Em Caio Fernando Abreu, as marcas púrpuras do sarcoma de Kaposi, o tipo raro de câncer que era associado à aids, são reconhecidas no espelho da sala de sua mãe, em Linda, uma história horrível, conto introdutório do livro Os dragões não conhecem o paraíso (1988). Na série de crônicas epistolares Cartas para além dos muros, publicadas em 1996, na coluna quinzenal d’O Estado de São Paulo, o escritor vai contando aos poucos, ele não fala diretamente da aids, até o momento final de revelar a doença, com toda a carga de significados, na última carta. Trata-se mais de estilo do que um jogo de culpa ou vergonha sobre a aids. No caso do conto, 'Linda, uma história horrível', há, ainda, algo mais que a elipse. “A doença é entendida paulatinamente pelo leitor, com as poucas e crescentes pistas sugeridas pelo texto"16 (p. 85).

Depoimentos femininos sobre uma sorologia positiva são raros até hoje: o livro já mencionado de Valéria Polizzi e a autobiografia 5 anos comigo, de Thaís Renovatto, são dois dos exemplos. No YouTube, quatro eram os canais produzidos por mulheres em outubro de 2020: Raquel Baptista ${ }^{\text {iii }}$, Bia Nickytinha ${ }^{\text {iv }}$

iii Disponível em: https://www.youtube.com/channel/UCM3d6eY0oYDecRr1gaXMSdA/featured

iv Disponível em: https://www.youtube.com/channel/UCV9inJ9HZyTxTt970xyu4Rg 
(apelido virtual de Fabiana Gomes), ambas do Rio de Janeiro, a brasiliense Blenda Silvav , e a paulista Thaís

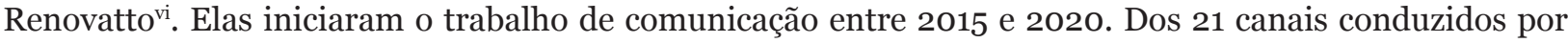
homens ( $84 \%$ do total) que tratam da sorologia positiva para o HIV em primeira pessoa, em 19 deles são homens jovens homossexuais que falam de sua orientação sexual. Houve, desde o começo da epidemia, um processo de invisibilidade das mulheres no campo do HIV/aids ${ }^{3}$.

A questão da maior prevalência do vírus HIV na população-chave de homens que fazem sexo com homens (HSH) não se apresenta como única possibilidade de explicação para a ausência de vozes femininas no debate do HIV e da aids. Ao contrário de outras epidemias, como a de sífilis, a mulher era apresentada em obras de arte ou em atlas de medicina, exercendo o papel de fonte disseminadora de doenças sexualmente transmissíveis; mas ocorre que, na epidemia de aids, o homossexual passa a ocupar esse lugar ${ }^{14}$. "Tudo aquilo que pode ser resumido na expressão 'passividade sexual' desafia uma ordem falocêntrica de poder que anula socialmente o sujeito em questão"16 (p. 60). É importante registrar que, na abordagem da sorologia positiva para o HIV, nos canais conduzidos por homens, não há menção à heterossexualidade em seus relatos.

\section{CONSIDERAÇÕES FINAIS}

Após quatro décadas de discursos produzidos sobre HIV/aids pela medicina, pela mídia, pela literatura, pela militância LGBTI e, mais recentemente, pelos canais de influenciadores digitais que relatam a sorologia positiva para o vírus HIV no YouTube, é possível perceber que as representações iniciais sobre o HIV/ aids não foram superadas totalmente no discurso. A possibilidade de usar o site de compartilhamento de vídeos para expressar a sorologia em primeira pessoa permite a análise de questões históricas e discursivas relacionadas ao vírus.

A "morte civil” (p.21), aspecto recorrente na narrativa de quem descobria sua sorologia positiva nos anos 1980, ressurge no interdiscurso dos relatos confessionais dos influenciadores. Hoje, o vírus HIV ainda aparece relacionado com a síndrome que foi construída como "provocada pelo indivíduo enquanto tal e enquanto membro de algum grupo de risco"4 (p. 55-56), como observou Sontag, ao diferenciar o discurso sobre a aids e sobre o câncer. As metáforas relacionadas à poluição, que foram formuladas para marcar a sífilis, são reacendidas em momentos de introdução, no Sistema Único de Saúde (SUS), de novas tecnologias de prevenção ao HIV, caso da Profilaxia Pré-Exposição (PrEP), como aconteceu em 2018.

Nas reportagens da mídia de abrangência nacional ou nas 'expressões pejorativas' usadas no cotidiano para referir-se aos adeptos da medicação, o julgamento moral é reafirmado. Mesmo com o avanço da tecnologia dos antirretrovirais e dos tratamentos preventivos adotados pelo SUS, com acesso garantido pela Lei 9.313/1996, a revelação da sorologia positiva carrega estigma e discriminação, demonstrados nos dados do estudo do UNAIDS Brasil, apresentado em 2019. As revisões periódicas na terminologia foram adotadas no campo científico, vale salientar, alterando as construções de significados, para desfazer as representações iniciais, como apresentado na análise dos dados dos resumos da Conferência Internacional de Aids, entre 1989 e 2014.

Neste artigo, em que observamos os diversos atores na disputa pelos significados e pela construção de narrativas sobre HIV/aids, os homens gays assumiram um protagonismo discursivo desde as primeiras informações sobre os casos de homens gays com um tipo raro de câncer, em 1981. Atualmente, na busca pelos canais do YouTube das pessoas que relatam suas experiências de sorologia positiva para o vírus, observamos que as vozes e os enredos se ampliaram. Mas, em sua maioria, os relatos são de homens gays, habitantes de metrópoles. É fundamental não comparar epidemias nem tentar olhar momentos históricos distintos da mesma maneira, como dito ao longo do texto, mas aprender, a partir do contexto histórico,

v Disponível em: https://www.youtube.com/channel/UCY452XLLJj5BmGp39dV8uyQ

vi Disponível em: https://www.youtube.com/channel/UCcMcGW5arg3rJGvbtrezRXA 
Reciis - Rev Eletron Comun Inf Inov Saúde. 2020 out.-dez.;14(4):857-69 | [www.reciis.icict.fiocruz.br] e-ISSN 1981-6278

que "o vírus atua à nossa imagem e semelhança, apenas reproduz e estende a toda população as formas dominantes de manejo biopolítico e necropolítico que já estavam trabalhando no território nacional”32 (p. 168).

\section{REFERÊNCIAS}

1. The HIV.gov timeline: Overview: History: A timeline of HIV and AIDS [Internet]. Washington: The Hiv. gov; 2019 [cited 2020 July 12]. Available from: https://www.hiv.gov/hiv-basics/overview/history/hivand-aids-timeline.

2. Camargo Júnior KR. As ciências da Aids e a Aids das ciências: o discurso médico e a construção da Aids. Rio de Janeiro: Relume Dumará; 1994.

3. Treichler PA. AIDS, gender, and biomedical discourse: current contexts for meaning. In: AIDS: the burdens of history [Internet]. Fee E, Fox DM, editors. Berkeley: University of California Press, c1988 [cited 2020 July 12]. Available from: https://publishing.cdlib.org/ucpressebooks/ view?docId=ft7t1nb59n\&chunk.id=d0e3182\&toc.id=d0e3182\&brand=eschol.

4. Sontag S. Aids e suas metáforas. São Paulo: Companhia das Letras; 1989.

5. Watney S. The spectacle of AIDS. October [Internet]. 1987 [cited 2020 Nov 16];43:71-86. Available from: https://www.jstor.org/stable/3397565?seq=1. doi: https://doi.org/10.2307/3397565.

6. Watney S. Safer sex as community practice. In: Aggleton P, Davies P, Hart G, editors. AIDS: individual, cultural and policy dimensions. London: The Falmer Press; 1990.

7. Parker R. Covid-19 e HIV/Aids: paralelos e lições. ABIA [Internet] 2020 abr. 20 [citado em 2020 nov. 16];Artigos. Disponível em: http://abiaids.org.br/covid-19-e-hiv-aids-paralelos-e-licoes/33941.

8. Gay men's health crisis records [Internet]. New York: The New York Public Library, Manuscripts and Archives Division; 1975-1978, 1982-1993, 1982-1999 [cited 2020 Oct 26]. Available from: http:// archives.nypl.org/mss/1126.

9. Galvão J. AIDS no Brasil: a agenda de construção de uma epidemia. Rio de Janeiro: ABIA; 2000.

10. Laurindo-Teodorescu L, Teixeira PR. Histórias da aids no Brasil, 1983-2003 [Internet]. V. 2, A sociedade civil se organiza pela luta contra a aids. Brasília, DF: Ministério da Saúde, Secretaria de Vigilância em Saúde, Departamento de DST, Aids e Hepatites Virais; 2015. [acesso em 2020 ago. 14]. Disponível em: https://unesdoc.unesco.org/ark:/48223/pf0000235558.

11. Volóchinov V. Marxismo e filosofia da linguagem. São Paulo: Editora 34; 2017.

12. Dancy-Scott N, Dutcher GA, Keselman A, et al. Trends in HIV terminology: text mining and data visualization assessment of international AIDS conference abstracts over 25 Years. JMIR Public Health Surveill [Internet] 2018 [cited 2020 Aug 13];4(2):e50. Available from: https://www.ncbi.nlm.nih.gov/ pmc/articles/PMC5960041/.

13. Índice de estigma em relação às pessoas vivendo com HIV/Aids: Brasil 2019 [Internet]. Brasília, DF: UNAIDS Brasil; 2019 [citado em 2020 fev. 05]. Disponível em: https://unaids.org.br/wp-content/ uploads/2019/12/2019 1206 Exec sum Stigma Index-2.pdf.

14. Gilman SL. AIDS and syphilis: the iconography of disease. October [Internet]. 1987 [cited 2020 Aug 13];43:87-107. Available from: https://www.jstor.org/stable/3397566?seq=1. doi: https://doi. org/10.2307/3397566.

15. Joffe H. Eu não, o meu grupo não: representações sociais transculturais da AIDS. In: Guareschi PA, Jovchelovitch S, organizadores. Textos em representações sociais. 8. ed. Rio de Janeiro: Editora Vozes; 2003.

16. Bessa MS. Histórias positivas: a literatura (des)construindo a aids. Rio de Janeiro: Record; 1997.

17. Treichler PA. AIDS, Homophobia, and biomedical discourse: an epidemic of signification. October [Internet]. 1987 [cited 2020 Aug 12];43:31-70. Available from: https://www.jstor.org/ stable/3397564?seq=1. doi: https://doi.org/10.2307/3397564.

18. Trevisan JS. Devassos no paraíso: a homossexualidade no Brasil, da colônia à atualidade. Rio de Janeiro: Record; 2000. 
19. Spink, MJP, Medrado B, Menegon VM, Lyra J, Lima H. A construção da AIDS-notícia. Cad. Saúde Pública [Internet]. 2001 [citado em 2020 ago. 13];17(4):851-62. Disponível em: https://www.scielo.br/scielo. php?pid=S0102-311X2001000400019\&script=sci abstract\&tIng=pt.

20. Daniel $\mathrm{H}$. Vida antes da morte = Life before death [Internet]. 3. ed. Rio de Janeiro: Abia; 2018. Português, Inglês [citado em 2020 ago. 12]. Disponível em: http://abiaids.org.br/wp-content/ uploads/2018/12/VIDA ANTES DA MORTE LIFE BEFORE DEATH site.pdf.

21. Carvalho CA. Visibilidades mediadas nas narrativas jornalísticas: a cobertura da Aids pela Folha de S.Paulo de 1983 a 1987. São Paulo: Annablume; 2009.

22. Blouin $\mathrm{CB}$, Chimot $\mathrm{E}$, Launère J. Aids, informação e prevenção: imprensa e medicina em busca de respostas. São Paulo: Summus Editorial; 1987.

23. Reis V. A segunda onda da Aids no Brasil. Abrasco [Internet] 2018 jun. 16 [citado em 2020 ago. 29];Notícias:Opinião. Disponível em: https://www.abrasco.org.br/site/noticias/opiniao/segunda-onda-daaids-no-brasil/34641/.

24. Carvalho CA, Azevêdo JHP. Do AZT à PrEP e à PEP: Aids, HIV, movimento LGBTI e jornalismo. Rev Eletron Comun Inf Inov Saúde [Internet]. 2019 [citado em 2020 ago. 13];13(2). Disponível em: https:// www.reciis.icict.fiocruz.br/index.php/reciis/article/view/1698/2269.

25. Matéria "A outra pílula azul" da revista Época é preconceituosa e peca na fundamentação [Internet]. Rio de Janeiro: ABIA; 2018 abr. 03 [citado em 2020 ago. 25]. Disponível em: http://abiaids.org. br/31417/31417.

26. Bruno F. Máquinas de ver, modos de ser: vigilância, tecnologia e subjetividade. Porto Alegre: Sulina; 2013.

27. Comicholi G. HDiário \#1 descoberta [Internet]. Gabriel Comicholi, produtor. 2016 abr. 01 [citado em 2020 set. 02] 1 vídeo: 1 min., sound, color. Canal no YouTube. Disponível em: https://www.youtube. com/watch?v=gQjsktEOUR4.

28. Arfuch L. O espaço biográfico: dilemas da subjetividade contemporânea. Rio de Janeiro: EdUERJ; 2010.

29. Pearl MB. AIDS literature and gay identity: the literature of loss. New York: Routledge; 2013.

30. Alós AP. Corpo infectado/corpus infectado: AIDS, narrativa e metáforas oportunistas. Rev Estud Fem [Internet]. 2019 [citado em 2020 ago. 19];27(3). Disponível em: https://www.scielo.br/scielo. php?script=sci arttext\&pid=S0104-026X2019000300205.

31. Sontag S. Assim vivemos agora. São Paulo: Companhia das Letras; 1995.

32. Preciado PB. Aprendiendo del vírus. In: Agamben G, Zizek S, Nancy JL, Berardi F, Petit SL, Butler J, et al. Sopa de Wuhan: pensamiento contemporáneo en tiempos de pandemias [Internet]. Buenos Aires: ASPO; 2020 [citado em 2020 abr 15]. p. 163-85. Disponível em: https://bit.ly/sopadewuhan. 